\title{
AO LEITOR
}

Pela primeira vez, Temáticas abre espaço para um conjunto de artigos que tratam de um tema comum. Diferente do que vinha ocorrendo até o $n^{\circ} 5 / 6$ da revista, ou seja, uma bem aproveitada gama de ensaios inseridos no conjunto da pesquisa universitária de cada um dos articulistas, tem-se, neste sétimo número, um espaço cujo intuito é trabalhar também com dossiês, o que faculta, tanto aos autores quanto à própria revista, a possibilidade de um debate mais profundo no tratamento dispensado a temas nuclearmente vinculados.

Neste sentido, os artigos presentes neste número de Temáticas possuem uma fonte comum de inspiração: todos eles foram escritos sob a influência do projeto "Homem, Saber e Natureza - Hosana", inicialmente idealizado como uma proposta interdisciplinar e coletiva envolvendo a investigação e análise de sistemas cognitivos de compreensão da lógica da natureza, e de formas culturais de apropriação ética e tecnológica do meio ambiente. Esse projeto, financiado pela Fundação de Amparo à Pesquisa do Estado de São Paulo (FAPESP) e coordenado pelo prof. dr. Carlos Rodrigues 
Brandão durante os anos de 1992 a 1995, foi o norteador da troca de idéias e leituras críticas entre os pesquisadores, o que resultou num grande volume de trabalhos científicos, entre eles os artigos aqui contidos.

Nessa nova experiência, a organização dos textos coube a Tereza D.P. Luchiari, membro do Conselho Editorial de Temáticas e pesquisadora do projeto acima indicado.

Os Editores

Temáticas, Campinas, 4(7):1-241, jan./jun. 1996 


\section{Autores}

THAIS MAR'TINS ECIILVLERRIA

Mestre em Antropologia Social e doutoranda em Ciências Sociais na Área de Agricultura e Questão Agrária (IFCH-Unicamp). Área de interesse: Avaliação de Impacto Ambiental.

\section{LÚCIA DA COSTA FLERREIRA}

Pesquisadora do Núcleo de Pesquisas Ambientais (Nepam/Unicamp) e Doutora em Ciências Sociais na Área de Ambiente, Tecnologia e Estrutura Social (IFCH-Unicamp). Área de interesse: Açào Social e Cidadania.

JOÑO LUI\% HOIIIIII.

Professor e pesquisador da Universidade São Francisco (Campus Bragança Paulista) e doutorando em Ciências Sociais na Área de Ambiente, Tecnologia e Estrutura Social (IFCH-Unicamp).

\section{CÉl.ta MARIA de TOLIEDO SIERRANO}

Pesquisadora do Núcleo de Pesquisas Ambientais (Nepam/Unicamp), Historiadora, Mestre em Sociologia e doutoranda em Ciências Sociais na Área de Ambiente, Tecnologia c Estrutura Social (IFCH-Unicamp). Área de interesse: Turismo e Meio Ambiente. 
Crismire: GADELLA TSUKIOKA

Mestranda cm Antropologia Social (IFCH-Unicamp)

Área de interesse: Antropologia e Meio Ambiente.

RUBIEN CAIXETA DE QUIIIROZ

Mestre em Antropologia pela (IFCH-Unicamp) e doutorando em Cinema e Antropologia pela Universidade de Paris X (Nanterre). Área de interesse: Antropologia Visual.

MARIA TIERE\%A D. P. LUCHIARI

Professora do Dpto.Sociologia (IFCH-Unicamp), Geógrafa, Mestre em Sociologia e doutoranda na Área de Ambiente, Tecnologia e Estrutura Social (IFCH-Unicamp). Área de interesse: Espaço Urbano, Meio ambiente e Populaçòes Litorâneas. 